\title{
Basal cell carcinoma within rhinophyma: coincidence or relationship?
}

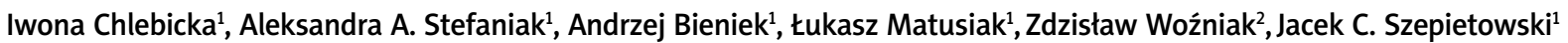

${ }^{1}$ Department of Dermatology, Venereology and Allergology, Wroclaw Medical University, Wroclaw, Poland

2Department of Pathology, Wroclaw Medical University, Wroclaw, Poland

Adv Dermatol Allergol 2021; XXXVIII (5): 855-857

DOI: https://doi.org/10.5114/ada.2020.99367

\begin{abstract}
Introduction: Rhinophyma is a relatively rare form of rosacea, while basal cell carcinoma (BCC) is the most frequent skin cancer in humans - both diseases prevail in the elderly.

Aim: To analyse patients with rhinophyma treated surgically in the Dermatosurgery Unit and look for possible cases with BCC within the rhinophyma.

Material and methods: We performed a retrospective review of all treated rhinophymas in the Dermatosurgery Unit in 2004-2019.

Results: Among 140 rhinophyma patients 2 (1.4\%) subjects with concomitant clinically diagnosed and histologically confirmed BCC were found, with BCC located in the hypertrophic tissue of the nose. There were no patients with BCC located in other anatomical regions of the skin. Both of these patients were in more advanced age.

Conclusions: Taking into consideration these two conditions: advanced age and anatomical location, typical for BCC, one may speculate that the development of BCC within rhinophyma is rather a simple coincidence. However, more numerous series of patients with rhinophyma are needed to clear the controversy of BCC within rhinophyma hypertrophic tissue.
\end{abstract}

Key words: basal cell carcinoma, rhinophyma.

\section{Introduction}

Basal cell carcinoma (BCC) is the most frequent skin cancer in humans. Rhinophyma is a relatively rare form of rosacea [1]. Both diseases prevail in the elderly [1]. Because of a rising number of patients with BCC within rhinophyma described in the literature, some scientists assume there could be a relationship between both conditions [2]. On the other hand, there are studies suggesting this is rather a simple coincidence [3].

\section{Aim}

The aim of this study was to analyse patients with rhinophyma treated surgically in the Dermatosurgery Unit and look for possible cases with BCC within the rhinophyma.

\section{Material and methods}

We performed a retrospective review of all treated rhinophymas in the Dermatosurgery Unit in 2004-2019.
All patients underwent surgical excision of hypertrophic tissue with subsequent electrodessication. Medical records of all those patients were examined to search for patients with concomitant BCC.

\section{Results}

Among 140 rhinophyma patients, 2 (1.4\%) subjects with concomitant clinically diagnosed and histologically confirmed BCC were found, with BCC located in the hypertrophic tissue of the nose. The rest of patients did not have any suspicion of neoplastic lesions within rhinophyma tissue. There were no patients with BCC located in other anatomical regions of the skin.

The first patient was a 65-year-old man with about 10 years' history of rhinophyma. He had not had any treatment for rhinophyma as he was not aware of any possibilities. His family doctor referred him to our centre. On admission the patient presented with hypertrophic nodules with telangiectasias and pustules predominantly on the lower two-thirds of the nose. Sebaceous discharge

Address for correspondence: Prof. Jacek C. Szepietowski MD, PhD, Department of Dermatology, Venereology and Allergology, Wroclaw Medical University, 1 Chałubińskiego St, 50-368 Wroclaw, Poland, phone: +48 7178422 86, fax: +48 713270942 , e-mail: jacek.szepietowski@umed.wroc.pl Received: 2.07.2020, accepted: 20.08.2020. 

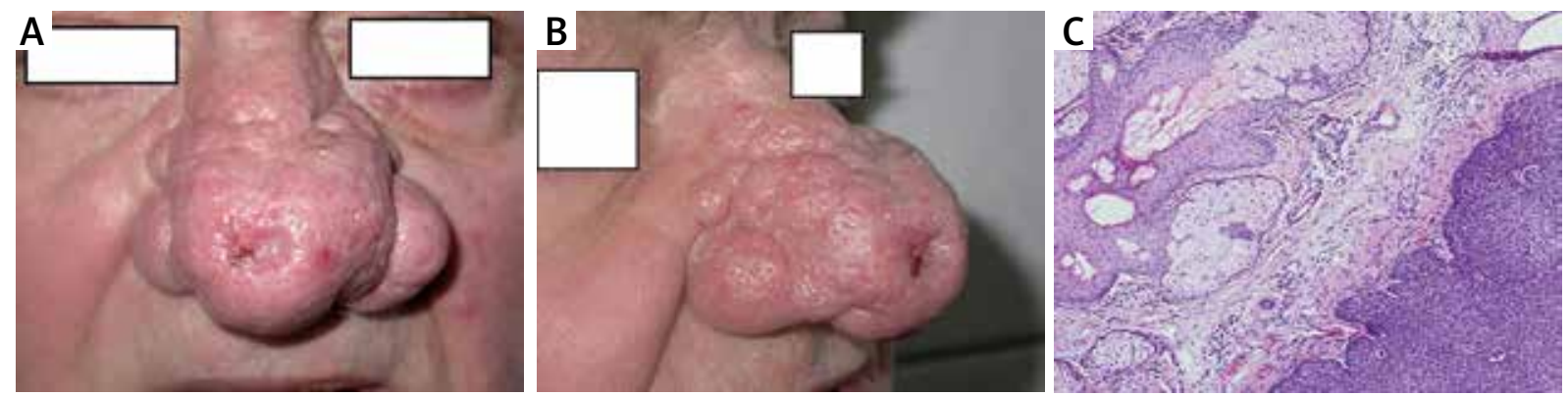

Figure 1. A, B - First case: lesion on the top of the nose of a diameter of $10 \times 10 \mathrm{~mm}$ with a pearly border, central depression with small erosion. C - Histological result of excised nodular BCC with visible sebaceous hyperplasia and inflammation $(H+E, 100 x)$

from the dilated pilosebaceous units on the nose was observed.

Apart from rhinophyma he presented with the lesion on the top of the nose of a diameter of $10 \times 10 \mathrm{~mm}$ with a pearly border, central depression with small erosion (Figures 1 A, B). The clinical picture suggested BCC. The patient reported that the lesion appeared 2 years before. The patient was generally healthy, with no history of internal diseases and concomitant treatment. He did not declare alcohol abuse, sunburns and excessive UV exposure in the past. Two-step surgical treatment was performed. First, suspected BCC was excised with a clear security tissue margin and subsequently surgical treatment of hypertrophic tissue was performed. Histology revealed nodular BCC with sebaceous hyperplasia and inflammation (Figure $1 \mathrm{C}$ ).

The other patient was a 72 -year-old male who was admitted to our unit because of ulcerated nodule on the bridge of the nose (Figure 2), which was growing over 7 months. During the physical examination the patient additionally presented with erythema and telangiectasias on the nose and both cheeks as well as a small amount of hypertrophic tissue on the wings of the nose. He was treated for rosacea for 2 years with topical metro-

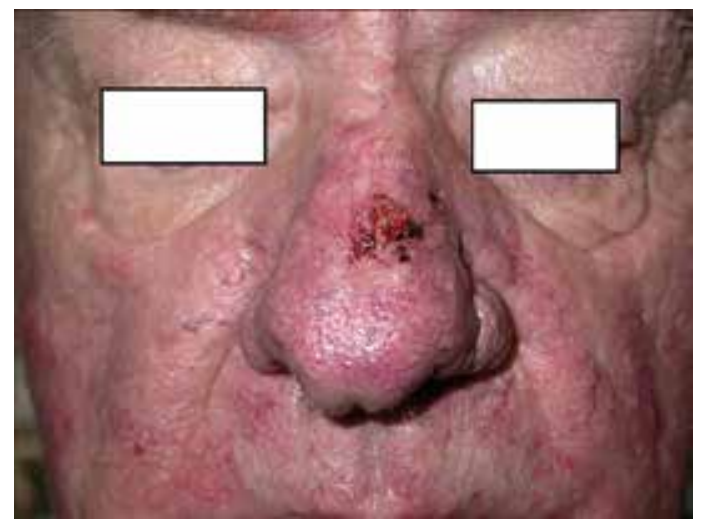

Figure 2. Second case: ulcerated nodule on the bridge of the nose nidazole and azelaic acid with only a slight-improvement. He denied alcohol abuse, sunburns and excessive UV exposure in the past. He was otherwise healthy without any concomitant medications. The lesion was surgically removed, and BCC was confirmed with histopathology.

\section{Discussion}

The first case of-BCC within rhinophyma was described in 1904 by Wende and Benz. Since that time only sporadic reports of BCC developing within rhinophyma have been described in the worldwide literature $[2,4,5]$.

Rhinophyma is a result of hyperplasia and fibrosis of the sebaceous glands in the skin of a nose. This condition is more common in men. The ratio of male to female patients with rhinophyma ranges from $5: 1$ to $30: 1$. Rhinophymas are seen more often in persons of English and Irish descent. It usually appears in the $5^{\text {th }}-7^{\text {th }}$ decade of life. BCC is the most common malignant skin tumour. $70-80 \%$ of all BCCs are localized on the head and neck area, especially on the nose [6].

The hypothesis that rhinophyma may be associated with carcinoma remains unclear. Epidemiological studies are very difficult to conduct because of rarity of rhinophyma, especially in some ethnic groups. The biggest analysis on BCC within rhinophyma was presented by Lazerri et al. [4] in 2012. They analysed all possible cases described in such databases as Medline, Ovid, Cochrane, Current Contents, PubMed, Google, and Google Scholar and found 28 such cases published. They also added 2 own similar cases. However, since 2012 only 1 case of $\mathrm{BCC}$ within rhinophyma has been described in the literature, in 2013 by de Seta et al. [3].

Some authors hypothesized that BCC can arise in 15$30 \%$ of rhinophyma [2]. Helwig and Acker [2] suggested that hyperplastic and hypertrophic modifications present within rhinophyma may trigger uncontrolled cellular activity of carcinoma [2]. Another theory of Silvis and Zachary [5] underlined the association between prior skin trauma and BCC. Novick et al. also emphasized a possible association of fibrous scaring which is present in rhinophyma with the development of BCC. Studies pub- 
lished by Curnier and Choudhary [7] are in contrast to the above-mentioned theories, namely Curnier and Choudhary did not find any relationships between rhinophyma and BCC. No patient in their studied group (62 male rhinophyma subjects) had clinically diagnosed BCC. Fisher [1] in his series of 33 patients had only 1 patient with BCC and rhinophyma. In our cohort of 140 rhinophyma patients only two BCCs were found. When we realize that rhinophyma occurs in patients in the $5-7^{\text {th }}$ decade of life, this age is a well-known risk factor for BCC. Moreover, the nose is considered as a very common location for BCC.

\section{Conclusions}

We do think that the development of BCC within rhinophyma is rather a simple coincidence, however, more numerous series of patients with rhinophyma are needed to be studied to clear the controversy of BCC within rhinophyma hypertrophic tissue.

\section{Conflict of interest}

The authors declare no conflict of interest.

\section{References}

1. Fisher WJ. Rhinophyma: its surgical treatment. Plast Reconstr Surg 2015; 45: 466-70.

2. Helwig EB, Acker MDW. Rhinophyma with carcinoma. Arch Dermatol 1967; 95: 250-4.

3. De Seta D, Russo FY, De Seta E, et al. Basal cell carcinoma masked in rhinophyma. Case Rep Otolaryngol 2013; 2013: 201024

4. Lazzeri D, Colizzi L, Licata G, et al. Malignancies within rhinophyma: report of three new cases and review of the literature. Aesthetic Plast Surg 2012; 36: 396-405.

5. Silvis NG, Zachary CB. Occult basal-cell carcinoma within rhinophyma. Clin Exp Dermatol 1990; 15: 282-4.

6. Lesiak A, Czuwara J, Kamińska-Winciorek G, et al. Rak podstawnokomórkowy skóry. Rekomendacje diagnostyczno-terapeutyczne Polskiego Towarzystwa Dermatologicznego. Przegl Dermatol 2019; 106: 107-26.

7. Curnier A, Choudhary S. Rhinophyma: dispelling the myths. Plast Reconstr Surg 2004; 114: 351-4. 